\title{
ARQUITETURA SOB SUSPEITA
}

\author{
ANA LUIZA NOBRE debate o que os arquitetos podem aprender \\ com os movimentos sociais
}

Não há dúvida de que a arquitetura no Brasil desfruta hoje de um protagonismo raro, talvez só comparável, em tempos recentes, ao período de maior expressão do moderno que teve em Brasília seu "canto do cisne”. As circunstâncias são muito distintas, no entanto. O que move a arquitetura no Brasil hoje é um clima de euforia que evidentemente não guarda nenhuma relação com o idealismo que fez surgir uma nova capital no Planalto Central em apenas três anos. A situação atual da arquitetura no Brasil tem a ver, isto sim, com um quadro de otimismo que começa a se delinear em 2008, com o início da extração de óleo da camada de pré-sal e os reflexos limitados da crise econômica mundial no país. Fatores aos quais se somam outros, como a política pública de geração de emprego e renda, a ampliação da classe média e a eleição do país como sede de uma sequência de megaeventos internacionais, tanto de origem religiosa quanto esportiva.

Em todo caso, e ainda que sob novo registro, conta-se mais uma vez com os apelos da "modernização" para levar adiante um modelo de desenvolvimento econômico que tem graves impactos sobre a já caótica dinâmica da urbanização brasileira. A disseminação em larga escala desse modelo, pautado por incentivos fiscais ao consumo desenfreado (com grande ênfase em eletrodomésticos e automóveis), é evidente: em Parauapebas, João Pessoa ou Rio de Janeiro, o que vemos hoje é um processo acelerado de transformações urbanas profundamente ancorado na força iconográfica da arquitetura, do qual esta em primeira instância se beneficia, em termos de um aumento expressivo de clientes, projetos e negócios. De modo que quase poderíamos dizer que se trata de mais um capítulo da relação entre a arquitetura e a "modernização de mercado" que caracteriza historicamente o Brasil - onde o mercado antecede o Estado nacional, e o Estado nacional antecede a democracia, conforme 
apontado por Tales Ab'Saber[1]. Mas o que chama a atenção no panorama atual é o boom da arquitetura em um nível impensável até poucos anos atrás, sobretudo para quem (como eu) estudou arquitetura na década de 1980, a assim chamada "década perdida", marcada pela recessão econômica e pela brutal desaceleração de todas as atividades ligadas à construção civil no Brasil.

Quem se der ao trabalho de examinar os últimos indicadores em termos de arquitetura no país pode se surpreender com números que chegam a desafiar os sinais de desaceleração da economia brasileira em 2013. Considere-se, por exemplo, o crescimento de $12 \%$ de registros profissionais na área de Arquitetura e Urbanismo[2], ou o aumento em termos de lançamentos de imóveis residenciais $(16,4 \%)$ e a comercialização de unidades residenciais novas (23,6\%) em São Paulo, em comparação com 2012[3]. Como se a arquitetura permanecesse imune às projeções declinantes que preocupam os economistas, seguimos assistindo, assim, à proliferação de caçambas, placas e canteiros de obras em cidades de médio e grande porte país afora, enquanto continuamos atraindo arquitetos, investidores, empresas e escolas de origem estrangeira em busca de oportunidades.

Por um lado, esse movimento indica que a arquitetura no Brasil - e, com ela, o urbanismo - superou um longo quadro depressivo que teve na década de 1980 um de seus piores momentos. O que, por si só, já poderia ser motivo de regozijo. Por outo lado, a onda atual de otimismo permite que a arquitetura no Brasil continue mostrando um alto grau de imunidade à crise disciplinar desencadeada no quadro internacional ao mesmo tempo em que se construía Brasília. Adrian Gorelik[4] já mostrou como Brasília acabou se constituindo numa espécie de ponto cego dentro do pensamento urbano dos anos 70-80, num quadro de grande desinteresse pela arquitetura no Brasil evidenciado nas sínteses historiográficas produzidas naquele período. Mas a autossatisfação conquistada com Brasília parece ter garantido à arquitetura brasileira também uma espécie de imunidade à crise do moderno, que se somou à repressão ao pensamento crítico no período militar e nos manteve à margem do debate teórico internacional por muitos anos. Não que tenham faltado vozes críticas no Brasil nos anos 1960-70, mas elas 


\begin{tabular}{ll|l}
\hline celeuma & número $4 \mid$ maio 2014 & dossiê \\
\hline
\end{tabular}

estiveram muito mais focadas numa discussão de teor políticoideológico que interessadas no debate disciplinar que forçou a reorientação do pensamento e da prática arquitetônica naquele momento.

Neste sentido, as manifestações de junho de 2013 podem abrir mais perspectivas para a arquitetura brasileira do que a princípio se supõe. Porque as manifestações não evidenciaram apenas a deterioração das condições de existência na cidade, o colapso de infraestrutura e serviços urbanos, as desigualdades sociais e territoriais, a violência, o eterno conflito entre interesses privados e públicos - tudo isso que tem estado na agenda da arquitetura, no mundo todo, e ganha uma dimensão ainda mais aguda no Brasil de hoje. O que veio à tona também foi a surpreendente insuficiência da imaginação dos arquitetos e urbanistas de hoje, no que diz respeito à cidade. Diante da potência imaginativa de dois desconhecidos de 20 anos de idade (ou nem isso), que surgiram na televisão nos primeiros dias de protestos como representantes do Movimento Passe Livre, pareceu subitamente sem viço até mesmo o pensamento de um arquiteto como Paulo Mendes da Rocha, consagrado internacionalmente justamente por conta da potência transformadora de sua arquitetura [5]. Quem ouviu o arquiteto uma semana antes, no mesmo programa de entrevistas, não poderia sequer sonhar que sua defesa do planejamento de transporte se mostraria tão acanhada frente à reivindicação básica do MPL: "transporte público gratuito e de qualidade, sem catracas e sem tarifa". Uma reivindicação talvez delirante (sobretudo no caso de uma metrópole como São Paulo), mas que ousou ir muito além da defesa do planejamento ou da simples redução do valor das tarifas de ônibus para colocar em pauta, com uma força absolutamente espantosa, o direito à cidade - ponto nevrálgico da discussão contemporânea em arquitetura a partir da década de 60.

Bem ou mal, a onda de manifestações acabou por desafiar os arquitetos a rever muitos dos seus pressupostos e categorias básicas, a começar pelo próprio conceito, já um tanto caduco, de “espaço público", que o movimento Occupy Wall Street colocou em xeque ao acampar no Zuccotti Park. Porque o parque, que na verdade é uma praça, se configura como um "espaço privado de uso público", categoria típica da legislação 
urbana nova-iorquina que incorpora o embaralhamento crescente entre público e privado nas metrópoles contemporâneas, do qual o exemplo mais extremo é provavelmente Hong Kong. E foi justamente essa condição que permitiu a ocupação desse valiosíssimo espaço a duas quadras de Wall Street e bem em frente ao canteiro de obras do novo World Trade Center. Sob muita tensão, claro, mas a salvo da invasão da polícia, pelo menos por dois meses.

No fundo, as manifestações e ocupações dos últimos tempos - ou, mais recentemente, os "rolezinhos"- talvez tenham muito mais a dizer aos arquitetos que boa parte das obras de arquitetura que têm surgido por aqui. Porque ao mesmo tempo em que a arquitetura salta aos olhos, no Brasil, como protagonista de um período de grandes transformações que tem sua expressão máxima na cidade (e o Rio de Janeiro tem se mostrado exemplar neste sentido, ao investir maciçamente em obras icônicas como o MIS, o MAR e o Museu do Amanhã), sua crise disciplinar vai se mostrando cada vez mais incontornável para os arquitetos e urbanistas brasileiros. E tudo indica que, se conseguimos de algum modo contornar a autocrítica que forçou a reorientação do pensamento e da prática projetual da arquitetura e do urbanismo na segunda metade do século $\mathrm{XX}$, dificilmente escaparemos da crise que se anuncia sob a expansão do mercado arquitetônico brasileiro e dos sinais de sucesso pessoal e profissional colhidos sob a pressão dos calendários impostos pelos programas políticos, investimentos e megaeventos. A não ser, é claro, que nos iludamos com os supostos sinais de modernidade que continuam a ser rotineiramente associados à arquitetura no Brasil.

O que se sugere é que a satisfação com o aumento do número de encomendas, concursos e espaço na mídia pode ser tão inevitável quanto perigosa, quando dispensa o posicionamento político e ideológico e encobre a fragilidade geral do campo da arquitetura no Brasil hoje revelada na formulação de programas federais que têm mostrado uma pobreza assombrosa em termos de arquitetura, limitando-se mesmo, em muitos casos, à reprodução da lógica do mercado imobiliário. Basta ver as obras já inauguradas do Minha Casa, Minha Vida, lançado em 2009 com a meta de construir 1 milhão de unidades habitacionais para famílias com renda de até dez salários mínimos. Ou, numa escala menor, 


\begin{tabular}{l|ll}
\hline celeuma & número $4 \mid$ maio 2014 & dossiê \\
\hline
\end{tabular}

os Centros de Artes e Esportes Unificados (CEUs), lançados no ano seguinte com previsão de instalar, em 4 anos, 360 unidades (com área entre 700 e 7000 m2) nas 27 unidades da federação.[6]

Em termos espaciais e construtivos, os primeiros resultados desses programas fazem pensar como a arquitetura neste país se tornou plenamente dispensável. Não seria preciso nem voltar a evocar Brasília para fazer notar como a arquitetura foi parte indissociável do projeto político do Brasil nos anos 50. Se olharmos as fotos da inauguração do Museu de Arte Moderna do Rio de Janeiro, por exemplo, veremos o mesmo JK subindo a rampa, sorridente, ao lado de Niomar Muniz Sodré e Carmen Portinho. Isso para não falar do apoio decisivo de Getúlio Vargas ao projeto de Lucio Costa e equipe para o edifício-sede do Ministério da Educação, no Rio, ícone máximo da arquitetura moderna no Brasil.

Pelo que vimos até agora, no entanto, até mesmo a produção do BNH/Banco Nacional de Habitação, profundamente vinculada ao regime militar e em sua maior parte tão vergonhosa, incluiu realizações e pesquisas bem mais inventivas que o Minha Casa, Minha Vida, seja no que diz respeito à organização da produção, ao desenvolvimento de técnicas e/ou sistemas construtivos[7]. E, por mais que nos últimos tempos tenham surgido críticas e propostas alternativas ao modelo do Minha Casa, Minha Vida por parte de arquitetos brasileiros e estrangeiros [8], ainda não se percebe, nem de longe, uma reflexividade crítica que acompanhe a difusão desses programas e os processos de transformação urbana pelos quais passam hoje muitas das cidades brasileiras. Muito menos um rebatimento mínimo entre transformações urbanas e produção artística, tão vital no caso de Nova York, por exemplo - onde, da crise econômica e urbana da década de 1970, emergiu uma forma de produção artística viabilizada por uma política urbana que beneficiou interesses imobiliários, mas também criou condições para a ocupação, por parte de artistas, de um conjunto expressivo de edifícios industriais degradados.[9]

Em termos de benefícios para as cidades, já não temos esperanças com relação à Copa do Mundo. A falta de planejamento e a absoluta falta de 
transparência com relação aos projetos só contribuíram para satisfazer a ganância da Fifa e das empreiteiras, enquanto contabilizamos o número escandaloso de 9 acidentes fatais em obras de estádios para o mundial de futebol - o último, por "desvio de função", segundo o Ministério do Trabalho.[10] Os problemas de mobilidade, acessibilidade, saneamento e habitação continuam crônicos em todas as cidades que sediam a Copa e permanecem longe de serem equacionados também na cidade que daqui a dois anos sediará a primeira Olimpíada da América do Sul. E ainda que o legado possa não ser propriamente uma obra, mas um avanço em termos de reflexão e capacidade crítica, a impressão que se tem até agora é que, mesmo com tantas oportunidades, a arquitetura no Brasil tem se movido nos últimos anos no máximo na superfície, e muito mais por pressões externas que por qualquer pressão exercida pela própria disciplina.

Por outro lado, a proeminência dada às imagens renderizadas de lançamentos arquitetônicos que preenchem as páginas dos jornais e os investimentos vistosos em infraestrutura que vêm redefinindo, nem sempre para melhor, nossas paisagens urbanas (a exemplo das pontes estaiadas, que se tornaram uma espécie de praga nacional), contrastam com um interesse crescente pelo repertório de usos - muitos deles imprevistos - que as cidades brasileiras têm revelado, em sua incrível vitalidade e criatividade. Coisas como o Baile do "Dutão", que existe há 20 anos sob o viaduto de Madureira, no Rio, subvertendo sua lógica rodoviarista e transformando-o num dos salões de baile mais elegantes da cidade. Ou o Pontilhão Cultural, criado pelo Coletivo Maré sob uma das passarelas da Linha Amarela, também no Rio, e destacado recentemente com o prêmio Deutsche Bank Urban Age - que também premiou o Plano Popular da Vila Autódromo, realizado por moradores de comunidade ameaçada de remoção, em conjunto com duas instituições acadêmicas (IPPUR/UFRJ e UFF).

Vinte anos depois que a crise do urbanismo foi tematizada pelo arquiteto holandês Rem Koolhaas, começam a surgir também no Brasil coletivos que testam novas formas de ação e associação, à revelia das estratégias de city-branding associadas a desastrosos processos de reestruturação urbana mundo afora. Operando numa escala pontual, 
com ações menos formalizadas que muitas vezes se constroem por desdobramentos, pequenos grupos como Basurama e Conjunto Vazio se alinham com uma rede de coletivos que vai se formando em várias cidades do mundo, procurando abrir novas perspectivas para a arquitetura do ponto de vista de sua prática política e projetual, com base na exploração de modos colaborativos que frequentemente envolvem também novos meios de financiamento e realização, a partir dos modelos cada vez mais conhecidos de crowd sourcing e crowd funding.

Tudo isso permanece um pouco invisível, mesmo para quem se dedica a acompanhar a produção de arquitetura no Brasil, e, claro, dificilmente chega a ganhar atenção da grande imprensa (que mais uma vez confirmou sua posição suspeita em relação à arquitetura ao silenciar-se por completo quanto ao prêmio internacional para o projeto da Vila Autódromo, que insiste em permanecer bem na entrada do Parque Olímpico da Barra da Tijuca[11]). Afinal, nada disso chega a ser muito, se comparado à arquitetura que costuma ser identificada com profissionais e obras de sucesso, e é frequentemente usada para atrair investidores e turistas. Ou mesmo em relação ao patrimônio arquitetônico que nos foi legado pela brilhante geração de arquitetos que construiu Brasília. Mas justo neste desequilíbrio pode estar a chave para o que pode ser um dos saldos mais desafiadores, para a arquitetura brasileira, dos novos movimentos sociais: a demanda por uma prática de projeto que vá além de sua concepção mais ordinária, como serviço voltado para a solução de problemas e necessidades, e considere seu potencial para formular questões e construir criticamente novas relações sociais.

[1] Ab’Sáber, Tales. “Cultura moderna e campo conservador no Brasil”. In Celeuma 1. http://www.mariantonia.prceu.usp.br/celeuma/?q=revista/1/dossie/cultura-... (http://www.mariantonia.prceu.usp.br/celeuma/?q=revista/1/dossie/culturamoderna-e-campo-conservador-no-brasil) (Acesso em 10.fev.2014)

[2] Segundo dados divulgados pelo Conselho de Arquitetura e Urbanismo do Brasil, que tomou esse crescimento como "considerável”, por ter passado de $99.000 \mathrm{em}$ 2012 para 111.868 no ano seguinte.Cf http://www.caubr.gov.br/?p=19451 (http://www.caubr.gov.br/?p=19451)(Acesso em 17.fev.2014)

[3] Conforme balanço do setor imobiliário do Município e das cidades da região metropolitana de São Paulo apresentado pelo Secovi-SP (Sindicato da Habitação). Ver http://balanco.secovi.com.br/2013-2/index.php 


\begin{tabular}{l|l|l|l|}
\hline celeuna & número 4 maio 2014 \\
\hline
\end{tabular}

número 10, 2012, pp. 213-239.

[5] Programa Roda-Viva, TV Cultura, 10/jun/2013 e 17/jun/2013

[6] O objetivo dos CEUs (Centros de Artes e Esportes Unificados) é integrar, num mesmo espaço físico, programas e ações culturais, práticas esportivas e de lazer, formação e qualificação para o mercado de trabalho, serviços socioassistenciais, políticas de prevenção à violência e inclusão digital, de modo a promover a cidadania em territórios de alta vulnerabilidade social das cidades brasileiras. A concepção, objetivos e projetos arquitetônicos de referência dos CEUs foram desenvolvidos por uma equipe multidisciplinar e interministerial que desenvolveu três modelos de CEUs, previstos para terrenos com dimensões mínimas de $700 \mathrm{~m}^{2}$, $3.000 \mathrm{~m}^{2}$ e $7.000 \mathrm{~m}^{2}$. Ver http://ceus.cultura.gov.br (http://ceus.cultura.gov.br) (Acesso em 01.jan.2014)

[7] Ver Nobre, Ana Luiza. Fios Cortantes. Projeto e Produto, Arquitetura e Design no Rio de Janeiro (1950-60). PUC-Rio, Dep. de História, 2008 (tese de doutorado) e Koury, Ana Paula. Proposições para a produção da arquitetura no Brasil (1960-70). FAU-USP, 2005 (tese de doutorado).

[8] Algumas dessas propostas foram reunidas na exposição "Modos de Habitar", realizada no Museu da Casa Brasileira no âmbito da X Bienal de Arquitetura de São Paulo, em 2013.

[9] Refiro-me ao que foi definido, em exposição recente no Whitney Museum, como "loft performance", e sua correspondência com a legislação urbana novaiorquina, que a partir de 1971 passou a permitir a artistas cadastrados na prefeitura viver e trabalhar no mesmo espaço, desde que este tivesse determinadas características (como origem industrial e dimensões avantajadas em relação aos padrões de habitação em Manhattan) e estivesse contido nos limites de uma área definida em grande parte pelo bairro do SoHo. Ver Sanders, J. e Hoberman, J. "Rituals of rented island. Object theater, loft performance, and the new psychodrama- Manhattan, 1970-1980" (Whitney Museum, 2013).

[10] Contratado como montador, o operário morto na Arena Pantanal, Cuiabá, em maio de 2014, atuava como eletricista, sem capacitação nem equipamento de segurança. Ver http://www.estadao.com.br/noticias/esportes, operario-morto-emacidente-n... (http://www.estadao.com.br/noticias/esportes, operario-morto-emacidente-na-arena-pantanal-estava-em-desvio-de-funcao, 1164225,0.htm)

[11] As remoções na Vila Autódromo foram iniciadas em março de 2014, depois de um longo movimento de resistência popular. De acordo com a Secretaria Municipal de Habitação, 452 das 583 famílias existentes no local optaram por transferir-se para um apartamento no Parque Carioca (conjunto habitacional recém-construído dentro do Programa Minha Casa Minha Vida), ou receber uma indenização para deixar suas casas. As demais resistem no local, onde se mobilizam para construir uma creche com os recursos do prêmio internacional recebido. Ver http://esporte.uol.com.br/rio-2016/ultimas-noticias/2014/04/09/defensori... (http://esporte.uol.com.br/rio-2016/ultimas-noticias/2014/04/09/defensoria-daaval-a-demolicao-e-rio-remove-bairro-por-olimpiada-de-2016.htm;) http://www.canalibase.org.br/demolicoes-aumentam-pressao-na-vila-autodromo/ (http://www.canalibase.org.br/demolicoes-aumentam-pressao-na-vila-autodromo/) e http://oglobo.globo.com/rio/ex-moradores-da-vila-autodromo-festejam-vida... (http://oglobo.globo.com/rio/ex-moradores-da-vila-autodromo-festejam-vida-noparque-carioca-12311245) 
